\title{
21
}

\section{EM BUSCA DA ÉTICA DE ESCRITA CONTEMPORÂNEA}

Davi Lara ${ }^{1}$

\begin{abstract}
Resumo: Em sua famosa conferência "O que é um autor?" (1969), Foucault desenvolve o conceito de função-autor diferenciando-o daquilo que ele chama de "princípio ético de escrita" de seu tempo, que era marcado por uma indiferença quanto à voz autoral. Hoje, quase cinquenta anos depois, podemos dizer que a ética de escrita mudou radicalmente, se levarmos em conta o complexo fenômeno que se convencionou chamar "o retorno do autor". Sendo assim, cumpre perguntar: qual é a ética de escrita contemporânea? Para respondê-lo, analisamos o romance Soldados de Salamina (2001), de Javier Cercas, bem como a contribuição teórica recente de Giorgio Agamben (2007) e Daniel Link (2010). Por fim, arriscamos afirmar que a ética de escrita contemporânea consiste, justamente, na busca por uma ética de escrita, num movimento no qual o que importa é a procura e não a conclusão, o processo e não o acabamento. Palavras-Chave: Ética de escrita; Autoria; Literatura contemporânea; Javier Cercas.
\end{abstract}

\section{LOOKING FOR THE CONTEMPORARY ETHIC OF WRITING}

АвSTRACт: In his famous conference "What is an author" (1969), Foucault develops the author-function concept making a differentiation between it and the "ethical principle of writing" of his times, which was marked by an indifference to the authorial voice. Today, almost fifty years later, we could affirm the ethic of writing has changed radically if we take the complex phenomenon known as "the author return" into consideration. Thus, we ask: what is the contemporary ethic of writing? To answer that question, we analyze the Javier Cercas' novel Soldiers of Salamina (2001), as well as the theoretical contribution of Giorgio Agamben (2007) and Daniel Link (2010). Finally, we venture to affirm that the contemporary ethic of writing consists precisely in the search for an ethic of writing, in a movement in which what matters is the search and not the conclusion, the process and not the finish.

KEYwORDS: Ethic of writing; Authorship; Contemporary literature; Javier Cercas.

Apresentada pela primeira vez para o seleto público da Sociedade Francesa de Filosofia, em 1969, a conferência "O que é um autor?" de Michel Foucault é hoje uma das principais referências no debate em torno da autoria. Isso se deve, em grande medida, à originalidade com que aborda o tema se comparada com o modo com que o debate era conduzido no meio intelectual francês de então. Basta lembrar que, em 1968, poucos meses antes de Foucault dar sua célebre conferência, Roland Barthes publicou o igualmente célebre "A morte do Autor", espécie de manifesto a favor de uma concepção de literatura em que o modelo de autor herdeiro da tradição romântica não tinha mais lugar. Ao atacar a figura do autor autocentrado, Barthes resume, num tópico, o anseio coletivo pela renovação da perspectiva dos estudos literários em prol de maior rigor teórico, bem como pelo engajamento político contra o individualismo burguês.

Tendo em conta esse contexto, podemos compreender o início da conferência, em que Foucault menciona o estado atual da discussão em torno da autoria. Logo de entrada, ele aponta para aquilo que chama de "princípio ético de escrita", que, em seu tempo, era marcado pela indiferença em relação ao autor enquanto lugar de emissão dos discursos. Após analisar algumas formas com que essa indiferença se expressava não apenas na crítica, como também na literatura de então, ele desenvolve sua grande contribuição nessa conferência: a ideia do autor como função. A despeito da ética de escrita moderna, na qual a escrita é concebida como ato no qual o autor enquanto pessoa empírica não cessa de desaparecer, Foucault mostra que a categoria de autor não desapareceu completamente. Ao contrário, ainda existia como espécie de força fantasmagórica cuja prova de existência era a manutenção de algumas funções sociais, como a circulação, a classificação e o agenciamento dos modos de leitura dos diferentes discursos. Esta força fantasmagórica, que ocupa o núcleo vazio de uma série de funções relacionadas ao discurso, é justamente a função-autor.

1 Doutorando no Programa de pós-graduação em Literatura e Cultura da Universidade Federal da Bahia. Contato: laradavi2@gmail.com. 


\section{1 chicáa}

Não pretendo me deter na exposição desse conceito, pois isso me desviaria muito dos objetivos desse ensaio. Gostaria apenas de sublinhar um detalhe que não me parece tão enfatizado pelos comentadores, mas que ocupa um papel decisivo na construção do argumento central de Foucault. Refiro-me à oposição entre o conceito de função-autor em relação ao que ele chama de "princípio ético de escrita". Como já vimos, para o filósofo francês, a indiferença de seus contemporâneos para com a figura do autor não devia ser pensada como indício do desaparecimento concreto da categoria do autor, já que sua presença ainda se fazia - e se faz - sentir no modo de funcionamento de certos setores da sociedade. Esse teria sido o erro de seus precursores, que, dando o desaparecimento do autor como certo, substituíram a instância autoral por outras instâncias, como a escritura ou a obra, sem resolver o problema. Diga-se de passagem que o próprio Foucault, em artigo publicado em 1966 a respeito de Maurice Blanchot ${ }^{2}$, já havia defendido uma concepção de literatura e de filosofia impessoal muito próxima da que ele rechaça na conferência de 1969. Há aí, portanto, um desvio em relação à ideia impessoal dos discursos, tal como era concebida por seus contemporâneos (e por ele próprio, três anos antes), que proporciona um rendimento crítico e filosófico riquíssimo. Ao invés de ver a indiferença moderna pela voz autoral como indício de mudanças concretas da natureza da literatura, o filósofo a circunscreve ao âmbito individual, como um impulso íntimo (por isso, um princípio) que molda a ação da escrita (por isso, ético) dos escritores de seu tempo. Como tal, esse princípio ético não deve ser confundido com uma característica textual, como um traço de escrita ou uma marca de estilo. Longe disso, deve ser entendido como algo situado aquém do texto, como "um princípio que não marca a escrita como resultado, mas a domina como prática” (FOUCAULT, 2009, p. 268).

Seja como for, o importante aqui é assinalar que a elaboração do conceito de funçãoautor só foi possível devido a esse desvio que opõe duas diferentes formas de se sentir e abordar a autoria. De um lado, a função-autor, uma instância impessoal que exerce funções concretas em diversos setores da sociedade; de outro, o princípio ético de escrita, um impulso íntimo que se relaciona com o modo como os escritores encaram seu ofício. Neste ensaio, gostaria de me deter neste impulso ético. Como já disse, quando Foucault elaborou essas considerações, o autor não gozava de muito prestígio; e esse desprestígio tinha uma relação direta com a ética de escrita de então. Hoje, quase cinquenta anos depois, podemos dizer que a ética de escrita mudou radicalmente, se levarmos em conta a profusão de narrativas em que se observa a intrusão da voz autoral, a recente valorização do campo (auto)biográfico nos romances contemporâneos e todos os elementos do complexo fenômeno que se convencionou chamar de "o retorno do autor".

Sendo assim, cumpre perguntar: qual é o princípio ético que rege a escrita contemporânea? Qual impulso molda a escrita de nosso tempo, não como um sinal visível, não como uma marca, mas como uma miragem, como um devir? Qual é o principal afeto que os escritores mobilizam quando se propõem a entrar no jogo da escrita?

$\star \star \star$

Gostaria de começar minha investigação focalizando algumas contribuições teóricas recentes. De fato, a repentina revalorização da figura do autor é um fenômeno complexo que afeta diversas

2 O artigo se intitula "O pensamento do exterior" e está publicado no terceiro volume dos Ditos e Escritos do autor (Cf. FOUCAULT, M. Estética: literatura e pintura, música e cinema. Tradução Inês Autran Dourado. 2. ed. Rio de Janeiro: Forense Universitária, 2009). 


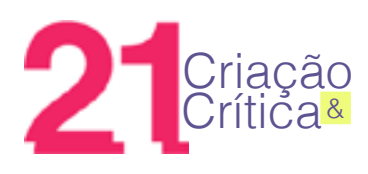

áreas do campo literário, dentre as quais a esfera crítica ocupa um lugar estratégico, devido ao poder de legitimação que possui, bem como ao caráter autorreflexivo. Uma das intervenções atuais mais influentes no debate em torno da autoria, nesse sentido, é "O autor como gesto", de Giorgio Agamben, que, além de tudo, tem a vantagem de travar um diálogo cerrado com a conferência de Foucault de 1969. Trata-se de um ensaio curto (8 páginas, na edição brasileira de que disponho), que, para fins didáticos, podemos dividir em duas partes: a primeira é reservada a uma releitura da conferência "O que é um autor?", da qual é retirada a problemática desenvolvida na segunda parte do texto. Na sua releitura do texto foucaultiano, o filósofo italiano aponta para a polarização radical entre o autor enquanto pessoa empírica, de um lado, e o autor enquanto função, de outro, que Foucault estabelece, para, em seguida, dedicar-se exclusivamente à instância impessoal da função-autor, dispensando um desprezo silencioso para com o sujeito que vive, escreve, dorme e caminha entre nós. Essa escolha é importante, pois deriva de uma opção metodológica consciente de Foucault, que, sem negar a existência do sujeito vivo, como alguns críticos afirmam, prefere voltar sua atenção para os dispositivos e agentes subjetivadores que capturam, organizam e regem os indivíduos em sociedade. Essa escolha nasce da compreensão de que os sujeitos só podem ser pensados como tais devido ao agenciamento dos dispositivos. A autoria seria apenas um desses dispositivos, por meio do qual um sujeito se reveste da dignidade da figura do autor e se torna proprietário de seu patrimônio intelectual, mas cobra um preço por isso: o do seu desaparecimento por trás dos mecanismos da escrita, o encobrimento de sua vitalidade por meio de um jogo no qual precisa fazer o papel de morto. Tendo isso em vista, Agamben lança o questionamento que o orienta em seu ensaio: "Mas de que maneira uma ausência poderia ser singular? E o que significa, para um indivíduo, ocupar o papel de um morto, deixar as próprias marcas em lugar vazio?" (AGAMBEN, 2007, p. 58).

A resposta de Agamben (também inspirada em Foucault, mas em outro texto do filósofo, o prefácio de $A$ vida dos homens infames) é que, para uma vida se deixar adivinhar por entre os dispositivos da autoria e da escrita, ela precisa pôr-se em jogo. Pôr sua própria vida em jogo, aqui, significa manter-se no âmbito do aberto, circulando por entre os dispositivos sem se permitir ser capturada por eles. A vida que se põe em jogo é como a vida dos homens infames: "Ela é apenas jogada, nunca possuída, nunca representada, nunca dita - por isso ela é o lugar possível, mas vazio, de uma ética, de uma forma-de-vida" (AGAMBEN, 2007, p. 60, grifos meus). O gesto é a chave conceitual com que o filósofo italiano sintetiza essa operação delicada, quase inapreensível, com que uma forma-de-vida se deixa adivinhar nas entrelinhas de um texto. A relação está no fato de que, do mesmo modo que, ao pôr-se em jogo, uma vida pode escapar das redes da representação, o gesto é o que "continua inexpresso em cada ato de expressão" (AGAMBEN, 2007, p. 59).

Assim, dentro da dicotomia proposta por Foucault, que opõe o sujeito capturado pelo dispositivo da autoria ao sujeito empírico, Agamben se impõe o desafio de seguir os rastros deste último nas bordas e nos vazios do primeiro. Dentro do complexo fenômeno da autoria, o que the interessa não é o sujeito psicológico que conforma a subjetividade do autor, pois "em nenhum lugar na psicologia encontramos algo parecido com um sujeito ético, com uma forma de vida" (AGAMBEN, 2007, p. 63, grifos meus). Não deixa de ser irônico que a conclusão do texto de Agamben, feita no rastro da conferência de Foucault, vá ao encontro das premissas dessa mesma conferência, na qual, como vimos, o âmbito ético ocupa um papel crucial. Porém, essa ironia só ficou clara para mim depois que compreendi melhor a amplitude das questões trabalhadas por Agamben em seu 


\section{1}

ensaio. E só pude compreendê-lo depois de ler outro texto, do crítico argentino Daniel Link, apresentado originalmente em julho de 2015 como conferência no I Festival Internacional de Literatura de Tucumán, em São Miguel de Tucumán, Argentina. "O escritor como 'forma-de-vida" é seu título, onde podemos notar, já de entrada, a filiação com Agamben, para quem, como acabamos de ver, a ideia da formadevida é crucial para desenvolver seu ponto de vista sobre o autor. Aliás, embora só o cite um par de vezes, bem no início do texto, pode-se dizer que o filósofo italiano está para Link como Foucault está para o italiano. Não é por acaso que, das variadas abordagens que poderia fazer do tema da autoria, o argentino escolha se deter "nesses momentos em que uma vida põe em jogo seu destino com a morte"3 (LINK, 2015, p. 3).

\section{$\star \star \star ~$}

De todos os textos que passaram por minhas mãos, "O escritor como forma-de-vida" é o que melhor representa a ética da escritura contemporânea, conforme a entendo. Em determinado momento do texto, falando sobre seus direcionamentos metodológicos, Daniel Link diz: "Ao escrever, pretendo [...] resgatar a palpitação do vivente nas imagens e na escritura dos dispositivos que pretendem capturá-lo e domesticá-lo" (2015, p. 2). Nesta afirmação, o escritor argentino declara o princípio ético que domina sua escrita, exatamente como nos termos foucaultianos, como um estímulo ético que se encontra na origem da sua escritura e que, num momento feliz de autorreflexão crítica, vem à superfície do texto. Para ele, o conceito que traduz essa palpitação de vida que atravessa os dispositivos sem ser reduzida por eles é o do clinamen: "o clinamen (esse desvio espontâneo no deslocamento dos átomos) bem pode ser a característica mais saliente do 'escritor', tal como podemos considerá-lo hoje, depois de tantos avatares e tantas desaparições." (LINK, 2015, p. 5).

Geralmente traduzido por declinação ou desvio, clinamen é um conceito grego, legado a nós por Lucrécio ${ }^{4}$ que designa o movimento espontâneo dos átomos. Desde suas origens, porém, o clinamen "apresenta-se como uma explicação física para uma constatação ética, a saber, a ação espontânea do homem" (FREIRE, 2014, p. 110). Ou seja, quando falamos nessa declinação aleatória do trajeto dos átomos, estamos fundamentando a autonomia da ação humana, a condição básica para a existência do sujeito ético. Saber disso, porém, não resolve o problema do autor como forma-de-vida. O problema reside justamente em saber como, na escritura, se resolve a negociação entre o movimento ingovernável da vida e os tentáculos onipresentes dos dispositivos (a escrita entre elas) em nossa sociedade. Levando em consideração a situação do autor (escritor, diria ele) no meio desse cabo de força, Link afirma:

Dominada a prática do escritor (a escrita) pela coação (o que não se pode deixar de fazer) e o azar (o que se faz ao acaso, sem razão alguma), essa forma-de-vida que

3 Trecho trazido por mim (assim como todas as traduções deste texto ao longo do ensaio) do original em espanhol.

4 Embora seja por meio de Lucrécio que conhecemos a elaboração do conceito, há indícios de que ele foi pensado inicialmente por Epicuro como uma reposta à crítica de Aristóteles à teoria atomista de Demócrito. Demócrito postulava que os átomos se encontravam no vazio, onde caíam todos numa mesma direção vertical, porém uns mais rápidos que outros, de modo a eventualmente chocarem-se entre si, provocando assim o movimento dos átomos e o nascimento da vida. Para Aristóteles, essa teoria não se sustenta porque, se os átomos estavam no vazio, não poderiam ter velocidades diferentes e, por conseguinte, não poderiam se chocar uns contra os outros, nem desviar suas rotas. O clinamen resolve esse problema afirmando que os átomos são acometidos de um desvio espontâneo, sem a necessidade de um estímulo inicial (Cf. FREIRE, 2014). 


\section{1}

o escritor seria não é o brinquedo de um destino, porém, tampouco é o produto de sua vontade: seu lugar é o (inter)dito. (LINK, 2015, p. 5).

Ou seja, para o argentino, a negociação entre vida e dispositivo não se resolve, ela fica em aberto, como a produção incessante de um eterno devir. Talvez isso explique por que, para ele, a escrita é uma atividade essencialmente incompleta. Em suas próprias palavras: "Escrever é se situar no lugar da ausência, é um assunto de devir, sempre inacabado, sempre em curso, e que transborda qualquer matéria vivível ou vivida. É um processo, quer dizer, um passo de Vida que atravessa o vivível e o vivido". Ou então: "Escrever não é alcançar uma forma (identificação, imitação, mímesis), nem mesmo persegui-la ('eu persigo uma forma que não encontra meu estilo'), é uma maneira de sabê-la inalcançável". Ou ainda: "Escrever é, definitivamente, tornar-se outra coisa que não escritor" (2015, p. 8).

Creio que nessa formulação da escrita (e do escritor) como uma busca ou um devir está a chave para responder a questão que preside este ensaio: qual é a ética da escrita contemporânea? A resposta, ao que me parece, está implícita na própria pergunta; de modo que, quando a respondemos, nos sentimos como os policiais d'“A carta roubada" de Poe quando descobrem que o envelope que procuravam esteve o tempo todo à vista: o princípio ético de escritura contemporânea é justamente a busca por uma ética de escritura. É a tentativa, sempre retomada, nunca alcançada, de fazer da escrita uma palpitação de vida.

Mas como essa ética de escrita se manifesta na literatura de nosso tempo? Para respondê-lo, gostaria de me voltar para Soldados de Salamina (2001), romance do escritor catalão Javier Cercas.

\section{$\star \star * t$}

Sempre que falo de Soldados de Salamina, em especial quando o foco é o protagonista, gosto de começar citando o início do romance:

Foi no verão de 1994, já faz agora mais de seis anos, que ouvi falar pela primeira vez do fuzilamento de Rafael Sánchez Mazas. Três importantes acontecimentos tinham então acabado de se produzir em minha vida: meu pai havia morrido, minha mulher me abandonara e eu abandonara minha carreira de escritor. (CERCAS, 2012, p. 13)

Como já disse em outra oportunidade (LARA, 2017), nestes dois períodos estão as bases sobre as quais o romance se desenvolverá. O primeiro aponta para o futuro do livro: Rafael Sánchez Mazas, cujo fuzilamento Javier Cercas ouvira falar pela primeira vez em 1994, é um escritor espanhol que entrou para os livros de história não como literato, mas como o fundador da Falange, partido de orientação fascista que preparou o terreno para o golpe que levou Franco ao poder em 1936. Ele será o personagem principal de um livro que Javier Cercas, o personagem, vai se dedicar a escrever ao longo do romance. Já o segundo período aponta para o estado de ânimo em que o protagonista se encontrava quando se decidiu a escrever a narrativa sobre Sánchez Mazas. Ele atravessara uma crise terrível, que começou com a morte do seu pai, se agravou com a desistência de escrever ficção e culminou com o fim de seu casamento. O centro desta crise, no entanto, era a sua relação com a literatura. Embora os livros que já havia publicado não tivessem obtido repercussão 


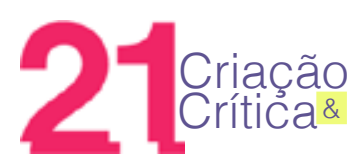

quase nenhuma, "a vaidade e a resenha elogiosa de um amigo daquela época" o persuadiram a tirar licença do jornal em que trabalhava para dedicar-se integralmente a escrever. "O resultado dessa mudança em minha vida foram cinco anos de angústia econômica, física e metafísica, três romances inacabados e uma depressão espantosa, que me derrubou no sofá diante do televisor durante dois meses" (CERCAS, 2012, p. 13).

Embora esse trecho ocupe apenas uma página, sua sombra se projeta por todo o restante do livro. Em primeiro lugar, a crise tem como consequência a desistência provisória por parte do personagem de escrever literatura. Digo provisória porque, ao fim e ao cabo, o narrador acaba retomando sua carreira de escritor, embora não se possa dizer que se torne um escritor igual ao que era antes da crise, na mesma medida que não se pode dizer que o tipo de literatura que passa a escrever seja o mesmo que havia escrito anteriormente. A mudança diz respeito ao estatuto da ficção. Depois de se recuperar da fase crítica de seu colapso psicológico, Javier Cercas, o personagem, parece usar a ficção, isto é, a literatura de invenção, como um bode expiatório para todos os seus problemas. No seu entendimento, a ficção é a culpada pelos maus bocados por que passou. Sendo assim, a última coisa que passava por sua cabeça era voltar a pedir licença do jornal para escrever um novo livro. Porém, é justamente isso o que faz. Depois que volta a trabalhar, o personagem toma conhecimento da intrigante história do quase fuzilamento de Sánchez Mazas e, pouco a pouco, por meio de uma série de eventos aparentemente fortuitos, vê-se completamente enredado nas desventuras do escritor falangista e dos seus amigos do bosque. Quando dá por si, já está decidido a escrever um livro: mas não um romance e sim uma narrativa real.

O entretecer desses eventos é narrado com maestria por Cercas (o personagem? O narrador? O autor?) na primeira parte do livro, "Os amigos do bosque". É uma pena não ter espaço, aqui, para comentar mais detidamente essa parte, pois os eventos aí apresentados funcionam como uma espécie de delimitação temática do livro, como uma narração do fascínio que a história de Sánchez Mazas vai despertando nele. Agora, porém, cumpre atentar para outra coisa igualmente, senão mais, importante: a encruzilhada afetiva e psicológica em que Cercas, o personagem, se encontrava quanto à literatura antes de se decidir a voltar a escrever. De um lado, ele havia renegado a ficção como elemento insidioso, de onde se seguia a resolução de não voltar a escrever ficção. Por outro lado, ainda continuava se considerando um escritor, como se a persona de escritor tivesse se amalgamado ao seu rosto de tal forma que já não podia se reconhecer sem ela. Isso fica muito claro num trecho do romance em que Cercas se encontra com Aguirre, um historiador que lhe ajuda com os detalhes acerca do fuzilamento de Sánchez Mazas, e Aguirre, para puxar assunto, mas também para matar a curiosidade de saber se suas informações iriam render um livro, pergunta-Ihe se estava escrevendo: "(quer dizer, se eu estava escrevendo um livro: como para quase todo o mundo, para Aguirre, escrever em jornal não é escrever). Um pouco irritado, porque nada irrita tanto um escritor que não escreve como perguntar-lhe o que está escrevendo, respondi que não" (CERCAS, 2012, p. 38).

O que mais me chama atenção neste trecho é a reação exagerada de Cercas, cuja irritação, ao que me parece, acusa seu envolvimento emocional mal resolvido com o ofício da escrita. Em segundo lugar, chama a atenção a crítica que faz a Aguirre por não considerar o trabalho jornalístico como uma escrita de fato, para logo em seguida ele próprio reafirmar essa distinção dando a entender que, de acordo com a imagem de escritor que tinha de si mesmo, escrever reportagens não Ihe bastava. Era preciso mais, algo no âmbito da criação. Neste ponto, a encruzilhada de 


\section{1}

Cercas fica bem clara: ele se sentia impelido a escrever, porém não se sentia à vontade com o modelo tradicional de literatura calcado na ficcionalidade. É dentro deste contexto que o enredo do livro se confunde com a busca por um novo tipo de literatura, ou, melhor dizendo, por uma nova ética de escrita - o que, dentro do contexto do romance, dá no mesmo. E é por isso que, apesar de boa parte do livro focar em questões aparentemente alheias ao personagem Javier Cercas, o grande eixo é a história de um escritor em busca de recuperar a vocação.

\section{*t*}

Vocação é um desses termos desgastados pelo tempo e pelo uso indiscriminado que a prudência aconselha evitar, se não quisermos ter o trabalho de espanar a poeira acumulada, para fazer surgir por detrás das antigas camadas um novo significado. De maneira quase automática, vocação está associada a certa concepção romântica de criação de acordo com a qual os escritores de gênio eram indivíduos que atendiam ao chamado de sua natureza especialmente dotada (com o perdão da nota etimológica: vocação deriva do termo latino vocatio, que significa o ato de chamar). No sentido em que o emprego aqui, o termo não tem nada a ver com esse significado. Ele ainda designa um chamado, mas esse chamado não chega a nós a partir da natureza, da pátria ou do desígnio divino. Ele está mais próximo daquilo que Barthes, no primeiro volume de $A$ preparação do romance, designa com a expressão "Quererescrever", um conceito-chave na virada subjetiva de Barthes, pois relaciona a escritura a um sujeito desejante, mesmo que a natureza desse desejo não seja de fácil delimitação: "O ‘Querer-Escrever' = atitude, pulsão, desejo, não sei bem: mal estudado, mal definido, mal situado" (BARTHES, 2005, p. 16).

Se não sabemos bem qual a natureza e a origem desse "Querer", pelo menos podemos dizer que ele não se encerra em si mesmo: "Por muito tempo", confessa Barthes, "acreditei que havia um Querer-Escrever em si: Escrever, verbo intransitivo - hoje tenho menos certeza. Talvez querer -escrever $=$ querer escrever algo $\rightarrow$ Querer-Escrever + Objeto" (BARTHES, 2005, p. 20). Dessa conjunção nasceria aquilo que Barthes denomina de fantasia de escritura, isto é, uma espécie de narrativa em que o sujeito se coloca ao lado de um objeto de escrita: "eu produzindo um 'objeto literário". De onde se segue a pergunta: "Que objeto?" (BARTHES, 2005, p. 20). Bem, isso varia. Para Barthes era um romance. Já para o Javier Cercas (auto)ficcional era uma "narrativa real". O mais importante, aqui, no entanto, não é exatamente o objeto, mas sim o impulso íntimo que Barthes chamava de fantasia de escritura. O foco não está tanto no produto quanto no processo, não tanto no ponto de chegada quanto no percurso. É por isso, inclusive, que podemos comparar o crítico francês e o escritor espanhol, pois ambos, cada um a seu modo, encontraram estímulo para continuar a escrever versando sobre a impossibilidade de se escrever de acordo com o modelo tradicional de literatura. Se é verdade que o livro de Cercas está mais próximo de um romance, do mesmo modo que o curso de Barthes está mais próximo de um caderno de notas para uma conferência, também é verdade que cada um deles opera uma ação deformadora quanto ao seu respectivo gênero de referência, a saber, o romance e a (performance) crítica, tendo como resultado um produto disforme e de difícil classificação.

Existem ainda outros pontos de contato entre o romance do espanhol e o curso do francês que valem a menção, como a questão da crise e a da renovação. Sabe-se que Barthes foi muito influenciado pelo luto decorrente da morte de sua mãe, sentimento que ele coloca como um marco que separa a vida entre um antes e um depois e obriga o enlutado a se renovar. Algo parecido 


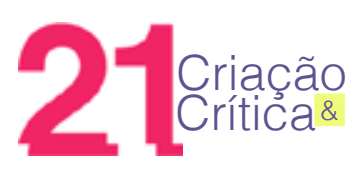

com o que acontece com Cercas, cuja crise é disparada pela morte de seu pai, do qual pouco se fala no livro, mas que é um marco na história do personagem e o impele a se reinventar. Para tratar do tema da divisória, Barthes faz referência ao célebre início da Divina Comédia - "Nel mezzo del cammin di nuestra vita" -, em que ele vê uma verdadeira declaração do sujeito enquanto escritor: "(Escritor = 'Não recalco o sujeito que sou')" (BARTHES, 2005, p. 4). Para tratar do tema da renovação, ele se utiliza da Vita Nova: "Ora, para aquele que escreve, que escolheu escrever, isto é, que experimentou o gozo, a felicidade de escrever (quase como "primeiro prazer"), não pode haver Vita Nova (parece-me) que não seja a descoberta de uma nova prática de escrita" (BARTHES, 2005, p. 9).

Com isso, dou por encerradas as aproximações com o Barthes de A preparação do romance e podemos voltar a Soldados de Salamina, emulando deliberadamente a frase de Barthes:-Ora, para quem experimentou a palpitação de vida ao escrever, como parece ser o caso de Javier Cercas, o protagonista do romance, não pode haver Vita Nova (parece-me) que não seja a descoberta de uma nova ética de escrita.

Por que insisto na questão da ética? Os leitores do romance certamente irão se lembrar das páginas finais, nas quais Cercas é acometido por uma revelação daquilo que procurava, quando toda inquietação que o move ao longo do romance se esvai numa espécie de catarse, que marca também o fim do romance, embora não sua resolução. Pode-se dizer que, nestas páginas finais, o autor tenha encontrado uma ética de escrita, ou que pelo menos a tenha sedimentado, acalmando o impulso que o impelia em sua busca. Mas o que nós, leitores, vemos ali não é nada mais do que a representação da subjetividade do personagem, já assentada, conciliada consigo mesma. A ética a que me refiro não tem nada a ver com a representação de uma subjetividade; diz respeito justamente àquilo que escapa aos processos de subjetivação, como um desvio, uma busca, um tatear no escuro. Sendo assim, quando falo que Soldados de Salamina pode ser lido como a saga de um escritor em busca de uma ética de escrita, mais importante do que o ponto de chegada (a ética de que ele porventura se apropriou), é o trajeto, o percurso. E uma das peculiaridades principais desse percurso é que ele faz coincidir o processo de elaboração de um livro com o processo de reconstituição de uma subjetividade dilacerada. Obra e sujeito, lado a lado.

\section{REFERÊNCIA}

AGABEN, G. O autor como gesto. In: Profanações. São Paulo: Boitempo, 2007.

BARTHES, R. A morte do Autor. In: O rumor da língua. Tradução de Mário Laranjeira. 3. ed. São Paulo: Martins Fontes, 2012.

A preparação do romance, vol. 1. Tradução de Leyla Perrone-Moisés. São Paulo: Martins Fontes, 2005.

CERCAS, J. Soldados de Salamina. Trad. Wagner Crelli. São Paulo: MEDIAfashion, 2012. (Coleção Folha. Literatura líbero-americana; v. 13)

FOUCAULT, M. O que é um autor? In: Estética: literatura e pintura, música e cinema. Tradução Inês Autran Dourado. Ed. 2. Rio de Janeiro: Forense Universitária, 2009. (Ditos e Escritos III)

O pensamento do exterior. In: Estética: literatura e pintura, música e cinema. Tradução Inês Autran Dourado. 2. ed. Rio de Janeiro: Forense Universitária, 2009. (Ditos e Escritos III) 
FREIRE, A. J. G. A natureza da alma e o clinamen: ação e liberdade em Lucrécio. 192 f. Tese (Doutoradao em Filosofia) - Programa Integrado de Doutorado em Filosofia, Universidade Federal do Rio Grande do Norte, Natal, Rio Grande do Norte, 2014.

LARA, D. S. de. A Sinuosa Dança do Real e do Ficcional em Javier Cercas. Revista Abehache, n. 9, v. 1, 2016, pp. 105-120.

LINK, D. El escritor como "forma-de-vida". Buenos Aires, 2015. Disponível em: <https://www.academia.edu/14001038/Daniel_Link._El_escritor_como_forma-de-vida_>. Acesso em: 3 jun 2017.

Recebido em: 28/08/2018 Aceito em: 25/09/2018

Referência eletrônica: LARA, Davi. Em busca da ética de escrita contemporânea. Criação \& Crítica, n. 21, p.106-114, nov. 2018. Disponível em: <http://revistas.usp.br/criacaoecritica>. Acesso em: dd mmm. aaaa. 